\title{
Clinical Characteristics \& Observation of Hospitalized Cases of Dengue Fever: A Study in Tertiary Care Hospital, Dhaka, Bangladesh
}

\author{
Md. Shafiul Hoque ${ }^{1 *}$, Probir Kumar Sarkar ${ }^{2}$, A.S.M. Nawshad Uddin Ahmed
}

${ }^{1}$ Associate Professor of Paediatrics, MD, Bangladesh Institute of Child Health, Dhaka Shishu (Children) Hospital, Dhaka 1207, Bangladesh

${ }^{2}$ Associate Professor of Paediatrics, FCPS, Bangladesh Institute of Child Health, Dhaka Shishu (Children) Hospital, Dhaka 1207, Bangladesh

${ }^{3}$ Professor of Paediatrics, FCPS, Bangladesh Institute of Child Health, Dhaka Shishu (Children) Hospital, Dhaka 1207, Bangladesh

\author{
DOI: $10.36348 /$ sjmps.2020.v06i12.004 $\quad$ | Received: 04.12.2020 | Accepted: 13.12.2020 | Published: 14.12 .2020 \\ *Corresponding author: Md. Shafiul Hoque
}

\section{Abstract}

Introduction: Incidence of dengue infection has increased around the world in recent decades and has become a major international public health concern. Early diagnosis is essential and clinical suspicion is based on the frequency of symptoms in the population. The exact clinical profile is important for management and prognosis. Objective: This study is an attempt to describe the Clinical Characteristics \& Observation of Hospitalized Cases of Dengue Fever: A Study in Tertiary Care Hospital, Dhaka, Bangladesh. Materials and Methods: A hospital-based prospective study was undertaken in the Paediatrics Dept. in Tertiary Care Hospital, Dhaka, Bangladesh (July -October 2018). NS1 antigen and IgM dengue antibody-positive cases were included. These patients were admitted with fever, myalgia, headache, vomiting, abdominal pain or bleeding manifestations. NS1 antigen and IgM dengue antibody was estimated using capture ELISA. The diagnosis of dengue fever, dengue hemorrhagic fever and dengue shock syndrome was based on the WHO (World Health Organization) criteria. Results: The study enrolled 101 patients of suspected dengue fever of whom $51(50.49 \%)$ were serologically confirmed to have dengue infection. $28(55.0 \%)$ patients were males and $23(45.0 \%)$ were females. 38 $(37.62 \%)$ patients had classic dengue fever while $12(11.88 \%)$ fulfilled the criteria of dengue hemorrhagic fever. Of those patients with dengue hemorrhagic fever, 6 patients had developed dengue shock syndrome. Conclusion: Dengue presents as a highly unspecific illness and is hardly recognized as a clinical entity by primary health care physicians. Dengue infection can have potentially fatal consequences, and to date, vector control methods to prevent the spread of the virus have been unsuccessful. Although there are promising vaccine candidates in development, further studies are required for a greater understanding of the humoral immune responses to Dengue infection and observation disease pathogenesis.

Keywords: Dengue, Dengue Shock Syndrome, Dengue Hemorrhagic Fever.

Copyright ( $) 2020$ The Author(s): This is an open-access article distributed under the terms of the Creative Commons Attribution 4.0 International License (CC BY-NC 4.0) which permits unrestricted use, distribution, and reproduction in any medium for non-commercial use provided the original author and source are credited.

\section{INTRODUCTION}

Incidence of dengue infection has increased around the world in recent decades and has become a major international public health concern. It is estimated that worldwide nearly 2.5 billion people continue to live at risk of contracting the infection while 50 million cases and 24,000 deaths tend to occur in 100 endemic countries every year [1]. In Bangladesh, epidemics are becoming more frequent. Involvement of younger age group and increase in the frequency of epidemics are indicators of higher incidence of infection. [2, 3] Dengue was first reported in 1780, when Benjamin Rush described this condition as "break bone fever". Dengue is a mosquito-borne viral illness caused by one of the four serotypes of the dengue virus (DENV; (DENV-1 to DENV-4) belonging to the family Flaviviridae. The virus serotypes are closely related but antigenically distinct. Dengue infections can result in a wide spectrum of disease severity ranging from an influenza-like illness (dengue fever; DF) to the lifethreatening dengue hemorrhagic fever (DHF)/dengue shock syndrome (DSS), which, if left untreated, are associated with mortality as high as $20 \%$ [4-6]. Early diagnosis is essential and clinical suspicion is based on the frequency of symptoms in the population. The first confirmed report of dengue infection in Bangladesh dates back to 1960 s, and since then more and more new states have been reporting the disease which mostly strikes in epidemic proportions often inflicting heavy morbidity and mortality [7]. Several fatal forms of the disease i.e., DHF, DSS have been reported in Bangladesh from time to time in different parts of Bangladesh. During all these epidemics infection occurred in active adults in the age group of 16-60 years [12, 13]. The common signs and symptoms observed were fever, headache, myalgia, arthralgia and 
bleeding manifestations have also been observed. The exact clinical profile is important for management and prognosis. This study is an attempt to describe the salient clinical as well as laboratory findings of serologically confirmed hospitalized cases of dengue fever.

\section{Historical Background}

Isolation and detection of dengue virus date back to World War II. Further characterization led to postulation of dengue virus as an agent involved in various past outbreaks exhibiting dengue-like symptoms. Dengue-like disease is illustrated in ancient Chinese manuscripts dating back to 992 and also to the 1600s in the West Indies [30]. The first detailed account of dengue shock syndrome (DSS) was recorded by Benjamin Rush in 1780 when an outbreak was reported in Philadelphia among people living near the Delaware River [31]. North America saw similar disease patterns in the 18th and 19th centuries along the Atlantic coast, on the Caribbean Islands, and also in the Mississippi basin [30]. Ae. aegypti mosquito as a vector of dengue virus was first discovered. However, it absolutely was solely in 1943-44 that the trendy chapter of infectious disease analysis started. This was when for the first time dengue virus was cultured and later isolated from suckling mice brain [32, 33]. Dengue virus belongs to the Arbovirus group of viruses that are transmitted through insect vectors. Virions are 40-50 $\mathrm{nm}$ in diameter and spherical in shape with $11 \mathrm{~kb}$ singlestranded RNA containing asingle open reading frame. Dengue virus consists of ten proteins, three of which are structural and seven nonstructural, and it has has four serotypes, namely DENV1, DENV2, DENV3 and DENV4. The Indian landmass is especially tormented by DENV2 and DENV3 serotypes. DENV1 and DENV4 were identified by studying neutralizing antibodies in the blood of volunteers in 1973 [12] while DENV1 and DENV2 were isolated as a consequence of the failure of viral strains to cross-protect human volunteers [35]. All four virus serotypes cause similar ill health, however severe and fatal harm unwellness is a lot of usually related to DENV2 and DENV3 infections. DEN2 type (genotype IV) and DEN3 (genotype III) are the most commonly isolated genotypes [36, 37].

\section{Materials ANd MethodS}

Settings: Paediatrics Dept. in Tertiary Care Hospital, Dhaka, Bangladesh to assess the Clinical Characteristics \& Observation Of Hospitalized Cases Of Dengue Fever.

Study design: Prospective cross-sectional study.

Study period: Four months spread among one seasons (July -October 2018).

Sample Size: Number of patients included in the study was (101).

\section{Inclusion Criteria}

a) Dengue patients admitted in ICU wards of Tertiary Care Hospital, Dhaka, Bangladesh.

b) Patients of all age groups, showing a temperature of $>38.5 \mathrm{oC}$ for $>24$ hours, and clinically diagnosed as having dengue fever.

\section{Exclusion Criteria}

a) Dengue cases with definite source of infection (e.g. respiratory or urinary tract infection, meningitis).

b) History of bleeding tendency since birth.

c) Immuno compromised patients.

A hospital-based prospective study was undertaken in the Department of Paediatrics Dept. in Tertiary Care Hospital, Dhaka, Bangladesh to assess the clinical profile \& observation of dengue infection in hospitalized patients. NS1 antigen and $\operatorname{IgM}$ dengue antibody-positive cases were included. These patients were admitted with fever, myalgia, headache, vomiting, abdominal pain or bleeding manifestations. NS1 antigen and IgM dengue antibody was estimated using capture ELISA. The diagnosis of dengue fever, dengue hemorrhagic fever and dengue shock syndrome was based on the WHO (World Health Organization) criteria. Only those patients were included in the study with classical features of dengue - fever with chills, body ache, headache, rash, bleeding manifestations and thrombocytopenia and had a positive ELISA test. Patients who had malaria and enteric fever were excluded from the study. Detailed history and clinical examinations were done. Hematological profiles and biochemical investigations were done at the time of admission and were followed by daily (or bi-daily) investigations as required until discharge. Signs of plasma leakage were assessed by chest radiograph and abdominal ultrasonography. Specific investigations were performed in patients who presented with neurological involvement (cerebrospinal fluid analysis, neuroimaging, electro diagnostic studies or muscle biopsy) or hepatic failure (viral markers, peripheral smear and serology for plasmodium falciparum, typhoid fever and leptospirosis). The study enrolled 101 patients of suspected dengue fever of whom 73 (34.93\%) were serologically confirmed to have dengue infection. Statistical analysis was performed by Chi -Square test done by using the Statistical Package "SPPS" for Social Sciences, with $\mathrm{p}<0.05$ taken as statistically significant.

\section{Disease and Treatment}

In 1997 the WHO classified clinical cases of dengue into three different subgroups based on the disease symptoms: dengue fever (DF); dengue hemorrhagic fever (DHF); and dengue shock syndrome (DSS) [32, 44]. Since overlap between these manifestations had been observed in 2009 this definition was revised as dengue with or without warning sign and severe dengue [32]. It is 
acknowledged by clinicians that the illness presents as a spectrum of disease instead of distinct phases. While the revised scheme is more sensitive to the diagnosis of severe dengue, and facilitates triage and case management, issues remain with its applicability, some experts considering that a more specific definition of warning signs is required. This calls for research into the diagnostic value of these warning signs on patient outcomes and the cost-effectiveness of the new classification system to ascertain if the updated classification requires yet further modification, perhaps to include elements of both systems [45]. Currently, there are no antiviral medications to target DENV so treatment of each patient is supportive, i.e. provided to alleviate their disease symptoms only [46]. The main goal of clinical management is to restrict or reverse increased vascular permeability, a hallmark of severe dengue, that leads to leakage of plasma into pleural and peritoneal cavities and shock [46]. In the absence of a cure, therefore, effective prevention, control and early management strategies are important to combat the disease and to reduce both the incidence and mortality rate arising from dengue. Implementation of effective mosquito control and surveillance strategies are critically required for more accurate early prediction and better preparation for outbreaks, as well as to directly reduce local transmission of DENV [44,47-49]. An efficacious vaccine is not currently available, but under development, and would also be beneficial as a prophylactic means to curb dengue incidence and mortality rate $[50,51]$.

\section{Classification and Reporting of Dengue Cases}

The WHO 1997 dengue classification system requires four essential criteria to be met for consideration as severe disease. Without any one of the four criteria, dengue patients will be classified as DF, although they might have already developed shock. This means that this classification system was not sensitive enough to include some cases of severe dengue [32]. Hence, not only did this result in inaccurate reporting but led to an avoidable potentially life-threatening situation for each misdiagnosed patient. This prompted the WHO (World Health Organization) within 12 years to revise its dengue classification system [32]. This was an apparent attempt to achieve better case management and to reduce mortality. However, in the decade since its introduction there is no evidence that switching to the 2009 classification system has had an effect in reduce mortality from dengue [32]. In part as a consequence, the mortality rate is unacceptably high in many developing countries, including Indonesia. Ignoring the update of the system, the 1997 classification is still used to report dengue in this country, where only DHF and DSS are diagnosed. Reporting dengue in Indonesia is mandatory within 72 hours after diagnosis. Severe secondary infection could explain the increase in CFR [20]. A possible reason is that nowadays, with different serotypes circulating in the population, DENV has become more pathogenic [73]. If the virulence of DENV remains stable, the CFR should be constant over time [73].

\section{Signs and Symptoms of Clinical Infection}

Further to a person being bitten by an infectious mosquito the incubation period of dengue prior to onset of illness is around 3-7 days [74]. There are a variety of common symptoms of dengue infection, including fever, headache, rash and myalgia [53, 66, 75]. Most clinical symptoms of severe dengue only manifest at late stage infection [47]. Severe plasma leakage is determined by shock (DSS) or fluid accumulation with respiratory distress and ascites. Severe bleeding and significant damage to major organs are often involved [32], affecting the liver (aspartate transaminase (AST) or alanine transaminase (ALT) $>1000 \mathrm{U} / \mathrm{L}$ detected), heart and central nervous system [76]. In Indonesia, predictors of severity are neither standardized nor used consistently. Clinicians assess for warning signs and symptoms for clinical case management, including spontaneous bleeding, plasma leakage (presence of ascites and pleural effusion), hepatomegaly, abdominal painhaemoconcentration, thrombocytopenia, and sharp increase of AST or ALT levels [75].

\section{Diagnostic Tests}

Diagnosis of dengue infection in the acute phase is important primarily for clinical care, but also facilitates the timely implementation of control measures and outbreak surveillance. Currently, two types of detection method are used to diagnose dengue if infection is suspected, namely direct and indirect tests [77]. Direct testing includes virus isolation [73] and real-time RT-PCR assay [78-80] of different DENV serotypes, and so can provide a differential diagnosis. This type of method is limited in its use due to the short duration and low titre of the viraemia in the peripheral blood of an infected person, up to 7 days after the onset of symptoms [81]. Indirect (serological) testing can be used to attain a rapid diagnosis, as early as the first day of fever, and involves detection in patient serum of developing immunoglobulin ( $\mathrm{Ig}$ ) $\mathrm{M}$ and $\mathrm{IgG}$ antibodies to DENV non-structural protein-1 (NS-1) [44]. These methods include ELISA, for which there is now a commercially available kit, and immune chromatography [81, 82]. Except for a few private institutions public and private hospitals in Indonesia do not yet perform dengue serotype surveillance [8]. Therefore, the great majority of dengue diagnoses are made purely by evaluation of clinical criteria using the outdated WHO (World Health Organization) 1997 classification system and supported by a basic haematological screen [9], including thrombocyte, leukocyte and haematocrit counts [83]. Not all Indonesian health services can utilize IgM/IgG and NS1 rapid tests as diagnostic tools due to the relative expense of the immunological reagents and a lack of 
medical laboratory expertise that is required to run each of these methods.

\section{Vector Locations, Behaviours and Breeding}

A recent detailed longitudinal study found that the most common mosquito species trapped in Indonesia from which DENV could be isolated was Ae. aegypti (90.9\%), while Ae. albopictus contributed only $9.1 \%$ of virus-positive samples. Ae. aegypti inhabits urban communities, living in close proximity to humans and resulting in more frequent bites [84] compared to Ae. albopictus which prefers more peri-urban and rural environments, which are thus less populated [85]. Both Ae. aegypti and Ae. albopictus may breed in waterholding vessels, including tyres, pots, tins and glass containers $[72,74]$. This is a significant problem in a country where more than half the inhabitants reside in metropolitan area. Rapid urbanization, as has occurred in the capital city in recent years, is associated with poor housing quality, limited safe water supply and restricted access to waste management. These encourage mosquito breeding and are significant contributing factors to the rising dengue incidencerate in Indonesia and other tropical low-income countries that are similarly experiencing accelerated population growth [75]. Moreover, a tropical climate and humid environment are conditions conducive to Aedes mosquito transmission of DENV [36, 84].

\section{Mosquito Prevention and Control}

Estimates of mosquito abundance, including measurable correlates such as egg production and numbers of adults caught in baited traps, are valuable indicators of the adequacy of disease prevention and control in any given location [1]. There are also several ways to eliminate places where the peri-domestic Ae. aegypti prefers to lay eggs in and surrounding homes [86-88]. In low-income tropical countries where dengue is a public health threat mosquito control is an ongoing necessity, especially in urban areas of high endemicity such as Jakarta [14], in order to reduce the presence of the Aedes vector and thereby to lower the rate of DENV transmission. This can be achieved by effective environmental management, including draining mosquito-breeding containers [86]. Larvicide treatment of pooled water is important to suppress the growth of mosquito populations and thus to reduce the risk of a sudden dengue outbreak [89]. Fogging, the technique of spraying a fine aerosol of fast-acting insecticide, is also used but is only effective for killing adult mosquitoes in enclosed spaces such as household rooms and basements [90]. The limitations to control of Aedes mosquito populations include financial constraints, insecticide resistance and insufficient community involvement [91, 92]. The prolonged use of chemicals insecticides has led to widespread development of mosquito resistance [93, 94], while its indirect effects on community health and the environment are for debate [90]. Likewise, larvicides, including the commonly used organophosphate temephos (marketed by BASF as Abate $\AA$ ), are toxic to marine wildlife in which they accumulate, and at high doses can cause nausea and dizziness in people. Moreover, it was reported that temephos did not reduce mosquitoes longterm [90].

\section{RESULTS}

The study enrolled 101 patients of suspected dengue fever of whom $51(50.49 \%)$ were serologically confirmed to have dengue infection. 28 (55.0\%) patients were males and $23(45.0 \%)$ were females. 38 $(37.62 \%)$ patients had classic dengue fever while 12 $(11.88 \%)$ fulfilled the criteria of dengue hemorrhagic fever. Of those patients with dengue hemorrhagic fever, 6 patients had developed dengue shock syndrome. Most of dengue cases occurred during the month of June to September depicts the role of rainy season on clustering of cases. Maximum number of cases 51 cases $(68.49 \%)$ was in the younger age groups as seen in Table1. As seen in Table- 2 fever was present in all cases and is the most common symptom followed by headache, myalgia, vomiting etc. Hemorrhagic manifestations were seen that included petechiae, ecchymosis, gum bleeding, hematuria, malena, hematemesis and epistaxis. Most common complicationswere hepatic dysfunction, renal failure, multi organ failure, encephalopathy and ARDS.

Table-1: Age distribution of patients with Dengue fever $(n=51)$

\begin{tabular}{|l|l|l|l|}
\hline Age & Male & Female & Total \\
\hline (Years) & $\mathrm{n}=31$ & $\mathrm{n}=20$ & 51 \\
\hline$<6$ months & 09 & 03 & 12 \\
\hline $10-20$ & 10 & 05 & 15 \\
\hline $21-30$ & 12 & 05 & 19 \\
\hline $31-40$ & 10 & 09 & 19 \\
\hline $41-50$ & 06 & 03 & 09 \\
\hline $51-60$ & 06 & 02 & 08 \\
\hline$>60$ & 04 & 02 & 06 \\
\hline
\end{tabular}

Among 51 suspected dengue cases 39 (76.5\%) cases were serologically dengue positive. Therefore 12 $(23.5 \%)$ serologically dengue negative cases were excluded from the study. Among the 39 serologically dengue positive patients $18(46.1 \%)$ were NS1 antigen positive, $13(33.3 \%)$ IgM antibodies and 8(20.6\%) both IgM and IgG antibodies positive. The distribution of the serologically dengue positive patients out of 51 clinically suspected cases were shown in Table-1. 
Table-2: Symptoms and complications of dengue fever $(n=51)$.

\begin{tabular}{|l|l|}
\hline Symptoms & Patients $(\mathbf{N}=\mathbf{5 1})$ \\
\hline Fever & 37 \\
\hline Headache & 27 \\
\hline Myalgia & 19 \\
\hline Vomiting & 21 \\
\hline Breathlessness & 15 \\
\hline Abdomen pain & 13 \\
\hline Bleeding tendency & 11 \\
\hline Skin rash & 7 \\
\hline Complications & \\
\hline Hepatic dysfunction & 24 \\
\hline Renal failure & 19 \\
\hline Encephalopathy & 8 \\
\hline Multi organ failure & 5 \\
\hline ARDS & 2 \\
\hline
\end{tabular}

Table-3: Distribution of the serologically dengue positive patients $(n=51)$

\begin{tabular}{|l|c|c|}
\hline & Number & percentage \\
\hline Total serology positive & 39 & 76.5 \\
\hline Total serology negative & 12 & 23.5 \\
\hline Serological test & Positive & percentage \\
\hline NS1 Ag & 18 & 46.1 \\
\hline IgM & 13 & 33.3 \\
\hline Both IgM and IgG & 8 & 20.6 \\
\hline
\end{tabular}

Among the study patients $28(55.44 \%)$ were male and 23(44.56\%) were female (Figure-1); 50 $(89.3 \%)$ from urban and $6(10.7 \%)$ rural area (Figure2 ). The age of the children range from 1 year to 18 years with a mean age of $6.66 \pm 3.69$ years. The age distribution of the patients are shown in Table- 2 .

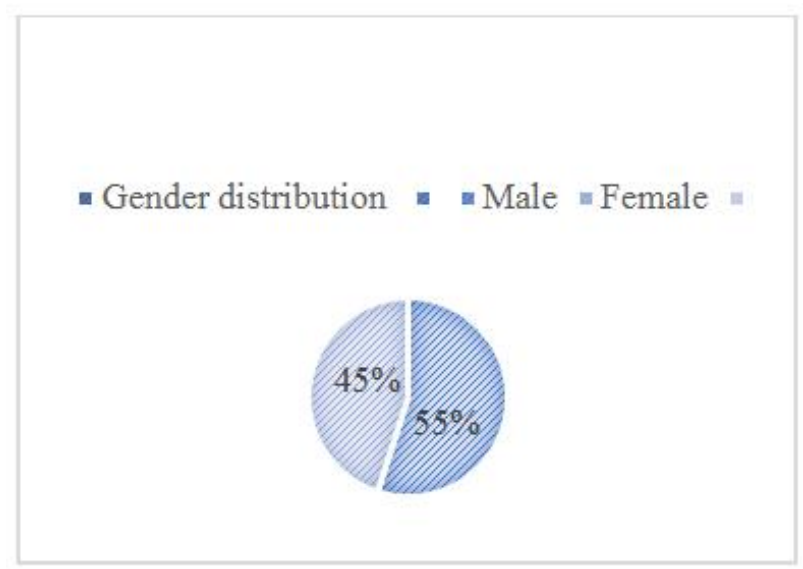

Fig-1: Geographical distribution of the patient

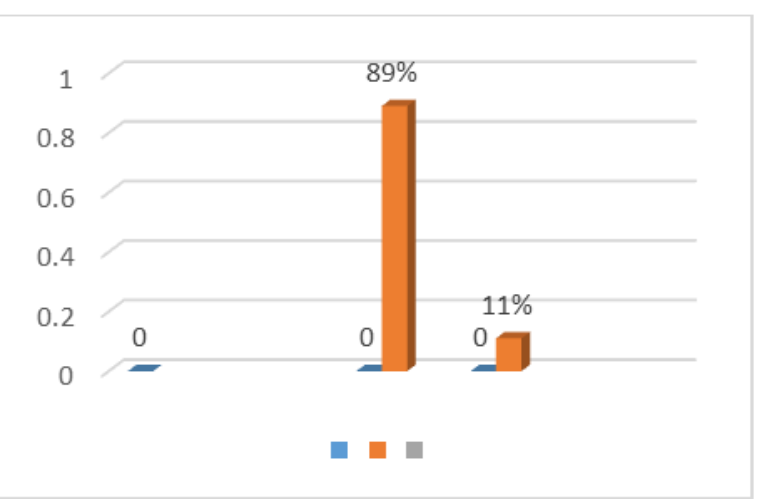

Fig-2: Geographical distribution of the patient

Deranged liver operate in dandy fever infection is a results of the direct impact of the virus on liver cells or the unregulated host response against the virus. Headache was conjointly seen less often compared to different studies. This has conjointly been documented in our study.

\section{DISCUSSION}

Dengue is a very important emerging disease of the tropical and sub-tropical regions. The identification is by clinical features but they can present with varied manifestation $[13,14]$. This study describes the clinical profile, laboratory features and outcome of DF/DHF/DSS in adult patients. The male to female ratio in this study was 2.04:1 respectively. The study revealed that majority of the cases was in the younger age group 51 cases $(50.49 \%)$. The clinical profile of dengue revealed that fever was the most common presenting symptom (100\%). Similar studies in past have also substantiated fever as being the most common presenting symptom. Abdominal pain and vomiting were due to the liver injury caused by the dengue virus. Other infections that cause fever and gastrointestinal symptoms such as typhoid, leptospirosis, and enteroviral infections are common in India and may often lead to a delay in the diagnosis of dengue. Complications observed in present study were hepatic dysfunction, renal failure, encephalopathy, multi organ failure, and ARDS. Deranged liver operate in dandy fever infection is a results of the direct impact of the virus on liver cells or the unregulated host response against the virus. Fulminant hepatic failure occurs because of acute severe hepatitis and massive necrosis of the liver, causing hepatic encephalopathy and even death [15]. An exclusive study on dengue shock syndrome conducted in Mumbai in 2003 reported hepatomegaly (97.4\%), altered sensorium (58\%), diarrhoea $(50 \%)$, rash (42\%), and cough $(38 \%)$ in a significant number of cases Headache was conjointly seen less often compared to different studies. This has conjointly been documented in our study. Most of the patients presented with dengue fever while dengue hemorrhagic fever and dengue shock syndrome were a minority group. Similar findings have also been reported from rural Maharashtra. Hemorrhagic 
manifestations included petechiae, ecchymosis, gum bleeding, hematuria, malena, hematemesis and epistaxis. Early clinical features of dengue infection are variable among patients, and initial symptoms are often non-specific; therefore, specific laboratory tests are necessary for an accurate diagnosis.[2,16] According to the US Centers for Disease Control and Prevention (CDC) and the WHO (World Health Organization) dengue guidelines [2], the clinical features of DF and DHF are sudden onset of fever, severe headache, myalgias and arthralgias, leucopoenia, thrombocytopenia, and hemorrhagic manifestations. It occasionally produces shock and haemorrhage, leading to death. Classic DF symptoms include fever, headache, retro-orbital pain, myalgias and arthralgias nausea, vomiting, and often a rash. Some DF patients develop the more serious form of the disease DHF with symptoms that include a decline in fever and presentation of hemorrhagic manifestations, such as microscopic hematuria, bleeding gums, epistaxis, hematemesis, melina, and ecchymosis. DHF patients develop thrombocytopenia and hemoconcentration; the latter is due to an increase in the concentration of blood cells resulting from the leakage of plasma from the bloodstream. These patients may progress into DSS, which can lead to profound shock and death if not treated. Advance clinical symptoms of DSS include severe abdominal pain, protracted vomiting, and a notable change in temperature from fever to hypothermia [5]. According to previous studies, there is a steady increase in the number of dengue patients over the past few years was noted. This is due to the rapid urbanization with unplanned construction activities and poor sanitation facilities contributing fertile breeding grounds for mosquitoes. Due to an increase in the alertness among medical fraternity following the initial epidemic and the availability of diagnostic tools in the hospital have contributed to the increased detection of cases [17]. A gradual increase in cases was noticed during rainy season. Pre-monsoon increase in the number of cases was noted in the months of March and April due to the stagnation of water, after a few bouts of pre-monsoon rainfall which facilitate vector breeding. These findings highlight that preventive measures against dengue infection should be taken during water stagnation periods after the initial bouts of rainfall and at the end ofmonsoon. In this study, DENV1 and DENV3 infections were observed but not DENV4 in 2018. In addition, DENV1 and DENV3 coinfections were detected in $18.5 \%$ cases in the year 2012, with higher tendency for hemorrhagic manifestations. Previous studies have shown that DENV2 and DENV3 serotypes were associated with haemorrhagic manifestations whereas Chandrakanta et al., [26], reported that $60 \%$ cases of DHF were associated with DENV1. Concurrent infections may present the possibility of recombination between viruses leading to the emergence of more virulent strains, underscoring the need for continued surveillance and serotyping.

\section{CONCLUSION}

Dengue is one amongst the key causes of dedifferentiated fever. It presents as an extremely broad wellness and is hardly recognized as a clinical entity by primary health care physicians. This study support additional studies on applying intervention measures to boost the diagnostic accuracy and exactness at the first tending level in dandy fever endemic regions. This study highlights the practician the importance of break bone fever to clinicians within the areas of medical specialty, manifestations, complications and outcome of the wellness. Dengue fever infection will have probably fatal consequences, and up to now, vector management strategies to forestall unfold of the virus are unsuccessful. Though there are promising immunizing agent candidates in development, additional studies are needed for a larger understanding of the body substance immune responses to dengue fever break bone fever infectious wellness infection and disease pathological process.

\section{REFERENCES}

1. World health Organization. (2002). Dengue and dengue hemorrhagic fever. Fact Sheet. No. 117.

2. World Health Organization. (1997). Dengue Hemorrhagic Fever: Diagnosis, Treatment, Prevention and Control. 2nd edition. Geneva, World Health Organization.

3. World Health Organization. WHO report on global surveillance of Epidemic prone infectious diseases?

4. WHO. (2008). Fact sheet $\mathrm{N}^{\circ}$ 117: Dengue and dengue hemorrhagic fever. Available:

5. Dengue and Dengue Hemorrhagic Fever: Information for Health Care Practitioners - CDC Division of Vector- Borne Infectious Diseases.Available:http://www.cdc.gov/ncidod/dv bid/dengue/dengue-hcp.htm.

6. WHO. (2009). Dengue Guidelines for Diagnosis, Treatment, Prevention and Control WHO 2009.

7. Tyagi, B. K., Hiriyan, J., Samuel, P., Tewari, S. C., \& Paramasivan, R. (2006). Dengue in Kerala: A critical review. ICMR Bull, 36(4-5), 13-22.

8. Konar, N. R., Mandal, A. K., \& Saha, A. K. (1966). Hemorrhagic fever in Kolkata. J Assoc Physicians India. 14:331-40.

9. Kader, A., Kandaswamy, P., \& Appavoo, N. C. (1997). Outbreak and control of dengue in a village in Dharmapuri, Tamil Nadu. Journal of communicable diseases, 29(1), 69-71.

10. Narayanan, M., Aravind, M. A., Thilothammal, N., Prema, R., Sargunam, C. R., \& Ramamurty, N. (2002). Dengue fever epidemic in Chennai-a study of clinical profile and outcome. Indian pediatrics, 39(11), 1027-1033.

11. Aggarwal, A., Chandra, J., Aneja, S., Patwari, A. K., \& Dutta, A. K. (1998). An epidemic of dengue 
hemorrhagic fever and dengu shock syndrome in children in Delhi. Indian pediatrics, 35, 727-732.

12. Balaya, S., Paul, S. D., D'lima, L. V., \& Pavri, K. M. (1969). Investigations on an outbreak of dengue in Delhi in 1967. Indian journal of medical research, 57(4), 767-74.

13. Chaturvedi, U. C., Mathur, A., Kapoor, A. K., Mehrotra, N. K., \& Mehrotra, R. M. L. (1970). Virological study of an epidemic of febrile illness with haemorrhagic manifestations at Kanpur, India, during 1968. Bulletin of the World Health Organization, 43(2), 289-293.

14. Kaur, H., Prabhakar, H., Mathew, P., Marshalla, R., \& Arya, M. (1997). Dengue haemorrhagic fever outbreak in October-November 1996 in Ludhiana, Punjab, India. The Indian Journal of Medical Research, 106, 1-3.

15. Karoli, R., Fatima, J., Siddiqi, Z., Kazmi, K. I., \& Sultania, A. R. (2012). Clinical profile of dengue infection at a teaching hospital in North India. The Journal of Infection in Developing Countries, 6(07), 551-554.

16. de Oliveira, S. A., Camacho, L. A. B., Bruno, L. F., de Gusmão, R. C., de Medeiros Pereira, A. C., Velarde, L. G. C., \& Siqueira, M. M. (2009). Acute arthropathy in patients with rash diseases: a comparative study. Clinical rheumatology, 28(9), 1067-1071.

17. Gubler, D. J. (1998). Dengue and dengue hemorrhagic fever. Clinical microbiology reviews, 11(3), 480-496.

18. Halstead, S. B. (2007). Dengue. The lancet, 370(9599), 1644-1652.

19. Mairuhu, A. T. A., Wagenaar, J., Brandjes, D. P. M., \& Van Gorp, E. C. M. (2004). Dengue: an arthropod-borne disease of global importance. European journal of clinical microbiology and infectious diseases, 23(6), 425433.

20. Cobelens, F. G., Groen, J., Osterhaus, A. D., Leentvaar- Kuipers, A., Wertheim- van Dillen, P. M., \& Kager, P. A. (2002). Incidence and risk factors of probable dengue virus infection among Dutch travellers to Asia. Tropical Medicine \& International Health, 7(4), 331-338.

21. Messer, W. B., Gubler, D. J., Harris, E., Sivananthan, K., \& De Silva, A. M. (2003). Emergence and global spread of a dengue serotype 3, subtype III virus. Emerging infectious diseases, 9(7), 800-809.

22. Hanna, J. N., Ritchie, S. A., Hills, S. L., van den Hurk, A. F., Spark, R. L., Phillips, D. A., ... \& Amadio, M. G. (2001). An epidemic of dengue 3 in far north Queensland, 1997-1999. Medical journal of Australia, 174(4), 178-182.

23. Gubler, D. J. (1997). Dengue and dengue hemorrhagic fever: its history and resurgence as a global public health problem. In: Gubler, D. J., \& Kuno, G. editors. Dengue and Dengue
Hemorrhagic Fever. Wallingford, UK: CAB International, 1-22.

24. Rush, B. (1789). An account of the bilious remitting fever, as it appeared in Philadelphia in the summer and autumn of the year 1780. Med Inq Obs Philadelphia, 1: 104-117.

25. Siler, J. F., Hall, M. W., \& Hitchens, A. P. (1926). Dengue: its history, epidemiology, mechanism of transmission, etiology, clinical manifestations, immunity, and prevention. Philipp. J. Sci, 29(12):1-304.

26. Bancroft, T. L. (1906). On the aetiology of dengue fever. Austral. Med. Gaz., 25, 17-18.

27. Hashem, A. M., Abujamel, T., Alhabbab, R., Almazroui, M., \& Azhar, E. I. (2018). Dengue infection in patients with febrile illness and its relationship to climate factors: A case study in the city of Jeddah, Saudi Arabia, for the period 2010 2014. Acta tropica, 181, 105-111.

28. Pang, X., Zhang, R., \& Cheng, G. (2017). Progress towards understanding the pathogenesis of dengue hemorrhagic fever. Virologica Sinica,32(1), 1622.

29. Masyeni, S., Yohan, B., Somia, I. K. A., Myint, K. S., \& Sasmono, R. T. (2018). Dengue infection in international travellers visiting Bali, Indonesia. Journal of Travel Medicine,25(1), tay061.

30. Cheng, K. J. G., Lam, H. Y., Rivera, A. S., Tumanan-Mendoza, B. A., Alejandria, M. M., \& $\mathrm{Wu}$, D. B. (2018). Estimating the Burden of Dengue in the Philippines Using a Dynamic Transmission Model. Acta Medica Philippina, 52(2):153-159.

31. Imrie, A. (2018). Dengue introduced by travellers, Australia. Microbiology Australia. 39: 67-71.

32. Low, G. K. K., Ogston, S. A., Yong, M. H., Gan, S. C., \& Chee, H. Y. (2018). Global dengue death before and after the new World Health Organization 2009 case classification: A systematic review and meta-regression analysis. Acta tropica, 182, 237-245.

33. Mishra, A. C., Arankalle, V. A., Gadhave, S. A., Mahadik, P. H., Shrivastava, S., Bhutkar, M., \& Vaidya, V. M. (2018). Stratified sero-prevalence revealed overall high disease burden of dengue but suboptimal immunity in younger age groups in Pune, India. PLoS neglected tropical diseases, 12(8), e0006657.

34. Wahyono, T. Y. M., Nealon, J., Beucher, S., Prayitno, A., Moureau, A., Nawawi, S., ... \& Nadjib, M. (2017). Indonesian dengue burden estimates: review of evidence by an expert panel. Epidemiology \& Infection, 145(11), 23242329.

35. Liebig, J., Jansen, C., Paini, D., Gardner, L., \& Jurdak, R. (2019). A global model for predicting the arrival of imported dengue infections. PloS one, 14(12), e0225193. 
36. Haryanto, B. (2018). Indonesia dengue fever: status, vulnerability, and challenges. Current Topics in Tropical Emerging Diseases and Travel Medicine, 5, 81-92.

37. Neiderud, C. J. (2015). How urbanization affects the epidemiology of emerging infectious diseases. Infection ecology \& epidemiology, 5(1), 27060.

38. World Health Organization. (2019). Dengue and severe dengue. https:// www.who.int/newsroom/fact-sheets/detail/dengue-and-severedengue.

39. Akter, R., Naish, S., Hu, W., \& Tong, S. (2017). Socio-demographic, ecological factors and dengue infection trends in Australia. PLoS One, 12(10), e0185551.

40. Maula, A. W., Fuad, A., \& Utarini, A. (2018). Ten-years trend of dengue research in Indonesia and South-east Asian countries: a bibliometric analysis. Global health action, 11(1), 1504398.

41. Woon, Y. L., Hor, C. P., Lee, K. Y., Anuar, S. F. Z. M., Mudin, R. N., Ahmad, M. K. S., ... \& Goh, P. P. (2018). Estimating dengue incidence and hospitalization in Malaysia, 2001 to 2013. BMC public health, 18(1), 946.

42. World Health Organization. (2018). A toolkit for national dengue burden estimation. https://apps.who.int/iris/handle/10665/277257.

43. Villanes, A., Griffiths, E., Rappa, M., \& Healey, C. G. (2018). Dengue fever surveillance in India using text mining in public media. The American journal of tropical medicine and hygiene, 98(1), 181-191.

44. Pan American Health Organization. (2016). Dengue guidelines for patient care in the region of the Americas, 2nd ed. http://iris.paho.org/ xmlui/handle/123456789/31207.

45. Hadinegoro, S. R. S. (2012). The revised WHO dengue case classification: does the system need to be modified?. Paediatrics and international child health, 32(sup1), 33-38.

46. Tate, M., \& Saini, G. (2018). A review on dengue and current status of its treatment. World Journal of Pharmacy and Pharmaceutical Sciences. 7: 570-582.

47. Suppiah, J., Ching, S. M., Amin-Nordin, S., MatNor, L. A., Ahmad-Najimudin, N. A., Low, G. K. K., .. \& Chee, H. Y. (2018). Clinical manifestations of dengue in relation to dengue serotype and genotype in Malaysia: A retrospective observational study. PLoS neglected tropical diseases, 12(9), e0006817.

48. Shukla, R., Ramasamy, V., Rajpoot, R. K., Arora, U., Poddar, A., Ahuja, R., ... \& Khanna, N. (2019). Next generation designer virus-like particle vaccines for dengue. Expert review of vaccines, $18(2), 105-117$.

49. Madzlan, F., Dom, N. C., Zakaria, N., Hasnan, S. N. A., Tiong, C. S., \& Camalxaman, S. N. (2018).
Profiling of dengue vectors breeding habitat at urban residential areas in Shah Alam, Malaysia. Serangga, 22(2):185-216.

50. Vu, T. T., Clapham, H., Thi, L. V., Le Thi, D., Vu, N. T., Nguyen, G. T., ... \& Le Huynh, D. T. (2019). A human ex vivo dengue virus neutralization assay identifies priority antibodies and epitopes for vaccines and therapeutics. BioRxiv, 516195.

51. Barde, P. V., Mishra, N., \& Singh, N. (2018). Timely diagnosis, use of information technology and mosquito control prevents dengue outbreaks: Experience from central India. Journal of infection and public health, 11(5), 739-741.

52. United Nations Department of Economic and Social Affairs. (2018). 68\% of the world population projected to live in urban areas by 2050, says UN. https://www.un.org/development/desa/en/news/po pulation/2018- revision-of-worldurbanizationprospects.html.

53. Mehta, S. R., Bafna, T. A., \& Pokale, A. B. (2018). Demographic and clinical spectrum of dengue patients admitted in a tertiary care hospital. Medical Journal of Dr. DY Patil Vidyapeeth, 11(2), 128-131.

54. Modi, A., Vaishnav, K., Pandya, R., Sahu, G., \& Naik, A. (2018). Urban dengue surveillance over sixteen years: Integration, trend analysis and participation of private medical sector. $J$. Commun. Dis, 50(3), 3.

55. Akanda, A. S., \& Johnson, K. (2018). Growing water insecurity and dengue burden in the Americas. The Lancet Planetary Health, 2(5), e190-e191.

56. Tran, B. X., Thu Vu, G., Hoang Nguyen, L., Tuan Le Nguyen, A., Thanh Tran, T., Thanh Nguyen, B., ... \& Ho, R. (2018). Cost-of-illness and the health-related quality of life of patients in the dengue fever outbreak in Hanoi in 2017. International journal of environmental research and public health, 15(6), 1174.

57. Bangert, M., Latheef, A. T., Dev Pant, S., Nishan Ahmed, I., Saleem, S., Nazla Rafeeq, F., ... \& Velayudhan, R. (2018). Economic analysis of dengue prevention and case management in the Maldives. PLoS neglected tropical diseases, 12(9), e0006796.

58. Harapan, H., Rajamoorthy, Y., Anwar, S., Bustamam, A., Radiansyah, A., Angraini, P., ... \& Akmal, I. (2018). Knowledge, attitude, and practice regarding dengue virus infection among inhabitants of Aceh, Indonesia: a cross-sectional study. BMC infectious diseases, 18(1), 96.

59. Nadjib, M., Setiawan, E., Putri, S., Nealon, J., Beucher, S., Hadinegoro, S. R., ... \& Wirawan, D. N. (2019). Economic burden of dengue in Indonesia. PLoS neglected tropical diseases, 13(1), e0007038. 
60. Adrizain, R., Setiabudi, D., \& Chairulfatah, A. (2018). Hospital-based surveillance: accuracy, adequacy, and timeliness of dengue case report in Bandung, West Java, Indonesia of 2015. Journal of Global Infectious Diseases, 10(4), 201-205.

61. Grange, L., Simon-Loriere, E., Sakuntabhai, A., Gresh, L., Paul, R., \& Harris, E. (2014). Epidemiological risk factors associated with high global frequency of inapparent dengue virus infections. Frontiers in immunology, 5, 280.

62. Indonesia Climate Change Sectoral Roadmap (ICCSR) Synthesis Report. (2010). Government of Indonesia, Jakarta. https://www.adaptationundp.org/sites/default/files/ downloads/indonesia_climate_change_ sectoral_roadmap_ic csr.pdf.

63. Diora, A., Ismah, Z., Irpani, T. H., Cahyo, R. D., \& Singh, M. S. M. (2017). Corelational Spatiotemporal Analysis Dengue Haemorrahagic Fever (DHF) With Settlement Condition In Palembang City, Indonesia. LIFE: International Journal of Health and Life-Sciences, 3(3):147157.

64. Bisnis.com. (2018). Kemenkes klaim kasus DBD di Indonesia Sudah Terkendali [Ministry of Health claims DHF cases in Indonesia are under control]. https://lifestyle.bisnis.com/read/20180717/106/817 431/ kemenkes-klaim-kasus-dbd-diIndonesiasudah-terkendali.

65. Imai, N., \& Ferguson, N. M. (2018). Targeting vaccinations for the licensed dengue vaccine: considerations for serosurvey design. PloS one, 13(6), e0199450.

66. Ayuningtyas, K. D., Rahardjo, S. S., \& Murti, B. (2019). Risk Factors of Dengue Fever: Application of PRECEDE-PROCEED Model. Journal of Epidemiology and Public Health, 4(1), 37-46.

67. Prayitno, A., Taurel, A. F., Nealon, J., Satari, H. I., Karyanti, M. R., Sekartini, R., ... \& Simmerman, J. M. (2017). Dengue seroprevalence and force of primary infection in a representative population of urban dwelling Indonesian children. PLoS neglected tropical diseases, 11(6), e0005621.

68. The Jakarta Post. (2019). Dengue death toll climbs to 132, eight regions declare emergency.https://www.thejakartapost.com/news/ 2019/01/31/ denguedeath-toll-climbs-to-132-eightregions-declare-emergency. Html.

69. BBC News Indonesia. (2019). Dengue fever mewabah: Pencegahan dengan jaga kebersihan dan tanam serai [Dengue fever is endemic: Prevention by maintaining cleanliness and planting lemongrass]. https://www.bbc.com/indonesia/indonesia47039921.

70. Nagaram, P. P., Piduru, P., Munagala, V. K., \& Matli, V. V. (2017). Clinical and laboratory profile and outcome of dengue cases among children attending a tertiary care hospital of South India. Int J Contemp Pediatr, 4(3), 1074-1080.

71. Tomashek, K. M., Lorenzi, O. D., Andújar-Pérez, D. A., Torres-Velásquez, B. C., Hunsperger, E. A., \& Munoz-Jordan, J. L. (2012). Clinical and epidemiologic characteristics of dengue and other etiologic agents among patients with acute febrile illness. Puerto Rico, 2015.

72. Luh, D. L., Liu, C. C., Luo, Y. R., \& Chen, S. C. (2018). Economic cost and burden of dengue during epidemics and non-epidemic years in Taiwan. Journal of infection and public health, 11(2), 215-223.

73. Soo, K. M., Khalid, B., Ching, S. M., \& Chee, H. Y. (2016). Meta-analysis of dengue severity during infection by different dengue virus serotypes in primary and secondary infections. PLoS One, 11(5), e0154760.

74. Kusmintarsih, E. S., Hayati, R. F., Turnip, O. N., Yohan, B., Suryaningsih, S., Pratiknyo, H., ... \& Sasmono, R. T. (2018). Molecular characterization of dengue viruses isolated from patients in Central Java, Indonesia. Journal of infection and public health, 11(5), 617-625.

75. Adam, A., Schüttoff, T., Reiche, S., \& Jassoy, C. (2018). High seroprevalence of dengue virus indicates that dengue virus infections are frequent in central and eastern Sudan. Tropical Medicine \& International Health, 23(9), 960-967.

76. Ajlan, B. A., Alafif, M. M., Alawi, M. M., Akbar, N. A., Aldigs, E. K., \& Madani, T. A. (2019). Assessment of the new World Health Organization's dengue classification for predicting severity of illness and level of healthcare required. PLoS neglected tropical diseases, 13(8), e0007144.

77. Gyawali, N., \& Taylor-Robinson, A. W. (2017). Diagnosis of dengue: strengths and limitations of current techniques and prospects for future improvements. Dengue-Immunopathology and Control Strategies. London: Intech Open, 55-73.

78. Nair, K. R., Oommen, S., Jagan, O. A., \& Pai, V. (2019). Detection of Circulating Dengue Virus Serotypes in a Tertiary Care Centre in Central Kerala, 2016. Int. J. Curr. Microbiol. App. Sci, 8(1), 2669-2678.

79. Wang, T. T., Sewatanon, J., Memoli, M. J., Wrammert, J., Bournazos, S., Bhaumik, S. K., ... \& Taubenberger, J. K. (2017). IgG antibodies to dengue enhanced for Fc $\gamma$ RIIIA binding determine disease severity. Science, 355(6323), 395-398.

80. Ambrose, J. H., Sekaran, S. D., \& Azizan, A. (2017). Dengue virus NS1 protein as a diagnostic marker: commercially available ELISA and comparison to qRT-PCR and serological diagnostic assays currently used by the state of Florida. Journal of tropical medicine, 2017: 8072491. 
81. Banerjee, A., Paul, U. K., \& Bandyopadhyay, A. (2018). Diagnosis of dengue fever: roles of different laboratory test methods. International Journal of Advances in Medicine, 5(2), 395-9.

82. Rockstroh, A., Barzon, L., Kumbukgolla, W., Su, H. X., Lizarazo, E., Vincenti-Gonzalez, M. F., ... \& Schmidt-Chanasit, J. (2019). Dengue virus IgM serotyping by ELISA with recombinant mutant envelope proteins. Emerging infectious diseases, 25(1), 112.

83. Pangestu, W. H., Mahmuda, I. N. N., \& PD, S. (2019). Perbedaan Profil Hematologi Rutin pada Penderita Demam Berdarah Dengue Anak dan Dewasa di RSUD Dr. Harjono Ponorogo (Doctoral dissertation, Universitas Muhammadiyah Surakarta).

84. Trewin, B. J., Darbro, J. M., Zalucki, M. P., Jansen, C. C., Schellhorn, N. A., \& Devine, G. J. (2019). Life on the margin: Rainwater tanks facilitate overwintering of the dengue vector, Aedes aegypti, in a sub-tropical climate. PloS one, 14(4), e0211167.

85. Cotchakaew, N., \& Soonwera, M. (2019). Toxicity of several botanical essential oils and their combinations against females of Aedes albopictus (Skuse) and Anopheles minimus (Theobald): Oviposition deterrent, ovicidal and adulticidal efficacies. Asian Pacific Journal of Tropical Biomedicine, 9(1), 29-39.

86. Singh, A., \& Taylor-Robinson, A. W. (2017). Vector control interventions to prevent dengue: current situation and strategies for future improvements to management of Aedes in India. $J$ Emerg Infect Dis, 2, 123.

87. Mood, B. S., \& Mardani, M. (2017). Dengue: a reemerging disease. Archives of Clinical Infectious Diseases, 12(1):e27970.

88. Strugarek M, Bossin H, Dumont Y (2019) on the use of the sterile insect release technique to reduce or eliminate mosquito populations. Applied Mathematical Modelling 68: 443-470.

89. Guzzetta, G., Trentini, F., Poletti, P., Baldacchino, F. A., Montarsi, F., Capelli, G., ... \& Melegaro, A. (2017). Effectiveness and economic assessment of routine larviciding for prevention of chikungunya and dengue in temperate urban settings in Europe. PLoS neglected tropical diseases, 11(9), e0005918.

90. Quirine, A., Wagman, J. M., Castro-Llanos, F., Achee, N. L., Grieco, J. P., \& Perkins, T. A. (2020). Community-level impacts of spatial repellents for control of diseases vectored by Aedes aegypti mosquitoes. PLoS computational biology, 16(9), e1008190.

91. Neumayr, A., Muñoz, J., Schunk, M., Bottieau, E., Cramer, J., Calleri, G., ... \& Serre-Delcor, N. (2017). Sentinel surveillance of imported dengue via travellers to Europe 2012 to 2014: TropNet data from the DengueTools Research Initiative. Eurosurveillance, 22(1), 30433.

92. Haziqah-Rashid, A., Chen, C. D., Lau, K. W., Low, V. L., Sofian-Azirun, M., Suana, I. W., ... \& Azidah, A. A. (2019). Monitoring Insecticide Resistance Profiles of Aedes aegypti (Diptera: Culicidae) in the Sunda Islands of Indonesia Based on Diagnostic Doses of Larvicides. Journal of medical entomology, 56(2), 514-518.

93. Faiz, M., Nazri, C. D., \& Chua, S. T. (2017). Spatial and temporal distribution of Aedes (Diptera: Culicidae) mosquitoes in Shah Alam. Tropical Biomedicine, 34(1), 118-126.

94. Marcombe, S., Chonephetsarath, S., Thammavong, P., \& Brey, P. T. (2018). Alternative insecticides for larval control of the dengue vector Aedes aegypti in Lao PDR: insecticide resistance and semi-field trial study. Parasites \& vectors, 11(1), 1-8.

95. Ministry of Health Republic of Indonesia. (2019). Kemenkes imbau seluruh daerah siaga DBD [Ministry of Health calls for dengue alert of the entire area]. http://www.depkes.go.id/article/view/1901180000 1/ kemenkes-imbauseluruh-daerah-siaga-dbd.html.

96. Orsborne, J., DeRaedt Banks, S., Hendy, A., Gezan, S. A., Kaur, H., Wilder-Smith, A., ... \& Logan, J. G. (2016). Personal protection of permethrin-treated clothing against Aedes aegypti, the vector of dengue and Zika virus, in the laboratory. PloS one, 11(5), e0152805. 